\section{BMJ Global Health}

\title{
Making sense of child, early and forced marriage among Syrian refugee girls: a mixed methods study in Lebanon
}

\author{
Susan Andrea Bartels, ${ }^{1}$ Saja Michael, ${ }^{2}$ Sophie Roupetz, ${ }^{3}$ Stephanie Garbern, ${ }^{4}$ \\ Lama Kilzar, ${ }^{2}$ Harveen Bergquist, ${ }^{5}$ Nour Bakhache, ${ }^{6}$ Colleen Davison, ${ }^{6}$ \\ Annie Bunting ${ }^{7}$
}

To cite: Bartels SA, Michael S, Roupetz S, et al. Making sense of child, early and forced marriage among Syrian refugee girls: a mixed methods study in Lebanon. BMJ Glob Health 2018;3:e000509. doi:10.1136/ bmjgh-2017-000509

Handling editor Stephanie M Topp

Received 2 August 2017 Revised 5 December 2017 Accepted 6 December 2017

\section{(1) CrossMark}

${ }^{1}$ Department of Emergency Medicine, Queen's University, Kingston, Ontario, Canada ${ }^{2}$ ABAAD Resource Center for Gender Equality, Beirut, Lebanon ${ }^{3}$ Department of Medical Psychology and Medical Sociology, University of Leipzig, Leipzig, Germany

${ }^{4}$ Department of Emergency Medicine, Beth Israel Deaconess Milton, Milton, Massachusetts, USA

${ }^{5}$ Department of Emergency Medicine, Brigham and Women's Hospital, Boston, Massachusetts, USA ${ }^{6}$ Department of Public Health Sciences, Queen's University, Kingston, Ontario, Canada ${ }^{7}$ Department of Social Science, York University, Toronto, Ontario, Canada

\section{Correspondence to} Dr Susan Andrea Bartels; susanabartels@gmail.com

\section{ABSTRACT}

Introduction The Syrian conflict has resulted in over 2.3 million child refugees in the Middle East and the prevalence of early marriage has reportedly increased among displaced Syrian families. This study explores the underlying factors contributing to child marriage among Syrian refugees in Lebanon with the goal of informing community-based strategies to address the issue. Methods In July-August 2016, trained interviewers collected self-interpreted stories in Lebanon using Cognitive Edge's SenseMaker, a mixed-method data collection tool. Participants included married and unmarried Syrian girls, Syrian parents as well as married and unmarried men. Each participant shared a story about the experiences of Syrian girls and then interpreted the story by plotting their perspectives on a variety of questions. Patterns in the responses were analysed in SPSS and the accompanying qualitative narratives were reviewed to facilitate interpretation of the quantitative results.

Results 1422 self-interpreted stories from 1346 unique participants were collected with $40 \%$ of shared stories focused on $(n=332)$ or mentioning $(n=245)$ child marriage. Quantitative data summarised the different perspectives of female and male participants. Syrian girls and mothers were more likely to share stories about protection/security and/or education and were more likely to report that girls were overprotected. Male participants were more likely to share stories about financial security as well as sexual exploitation of girls and more often reported that girls were not protected enough. Despite these gendered perspectives, many of the shared narratives highlighted similar themes of financial hardship, lack of educational opportunities and safety concerns around sexual and gender-based violence (SGBV).

Conclusions A complex myriad of factors contribute to early marriage including poverty, lack of educational opportunities and concerns about SGBV. Sexual exploitation under the guise of marriage is a reality for some Syrian girls. Gender-specific strategies to address child marriage might be more effective in reducing this harmful practice.

\section{INTRODUCTION}

The Syrian conflict has resulted in one of the worst humanitarian crises in recent

\section{Key questions}

What is already known about this topic?

- Child marriage is a human rights violation and a common form of sexual and gender-based violence (SGBV) that is associated with poverty and gender inequality.

- Vulnerability to early marriage can be exacerbated by armed conflict and rates of child marriage within Syrian refugee populations have reportedly increased during the current crisis.

What are the new findings?

- Some Syrian girls in Lebanon are choosing to marry early as a way out of unfavourable living conditions.

- Syrian parents perceive that the risk of SGBV and harassment is higher for Syrian girls in Lebanon than it was in Syria.

- Male and female respondents interpret their narratives about child marriage differently and emphasise different underlying factors contributing to early marriage.

\section{Recommendations for policy}

- Gender-specific strategies to reduce child marriage may be more effective given that men and women perceived child marriage differently and engaging men and boys should continue to be a priority.

- The findings support holistic interventions to address child marriage, including economic, social, educational and familial strategies.

- Improved safety for Syrian girls in Lebanon is essential and girls ought to be provided with safe spaces and safe modes of transportation, enabling them to socialise and access support.

history. ${ }^{1}$ As of January 2017, approximately 5 million Syrian refugees had fled to other countries and another 6 million people had been displaced within Syria, including in besieged areas without humanitarian access. ${ }^{2}$ The number of Syrian child refugees exceeds 2.3 million in the Middle East, ${ }^{3}$ with Lebanon hosting more than 500000 displaced Syrian 
children. ${ }^{4}$ Reports have documented the myriad of ways children have been impacted by the crisis including physical injuries, psychological stress, being orphaned or separated from family, food insecurity and lack of basic health services. ${ }^{36}$ Furthermore, many Syrian children are without access to formal education and are engaged in child labour to help support their families. ${ }^{378}$ Girls face additional gendered risks including harassment and sexual violence, and recent reports have raised concern over increases in the rates of child marriage within Syrian refugee populations. ${ }^{7-14}$ Although child marriage did occur in Syria prior to the war, with $13 \%$ of girls under the age of 18 reportedly married in 2006, forced displacement appears to have increased its prevalence ${ }^{12}$ and approximately $35 \%$ of Syrian refugee girls/women are now reportedly married before the age of $18 .^{15}$

Child marriage is defined as any formal or informal union where one or both parties is below the age of $18 .{ }^{16}$ Early marriage encompasses child marriage and includes situations that do not qualify as child marriage, such as marriages in which one or both spouses are below the age of 18 but have attained majority under state laws. ${ }^{17}$ Forced marriage is a marriage to which one or both of the spouses did not give their free and full consent. ${ }^{17}$ Child marriage, the focus of this research, is widely recognised as a human rights violation according to the Universal Declaration of Human Rights, ${ }^{18}$ the Convention on the Rights of the Child, ${ }^{19}$ the Convention on Consent to Marriage, Minimum Age for Marriage and Registration of Marriages ${ }^{20}$ and the Convention on the Elimination of All Forms of Discrimination Against Women. ${ }^{21}$ Although certainly a global issue, sub-Saharan Africa and South Asia have had the highest rates of child marriage historically, ${ }^{22} 23$ and poverty continues to be a major contributor, with many parents genuinely feeling that early marriage will secure their daughters' futures. ${ }^{24} 25$ The consequences of child marriage are profound and long lasting. Girls married at a young age are at high risk for complicated pregnancies and deliveries ${ }^{10}{ }^{11} 26-28$ and infants born to young mothers are at higher risk for neonatal death and stillbirth. ${ }^{7101219}$ Furthermore, girls who marry early are often at higher risk of intimate partner violence in comparison with those who marry as consenting adults $^{71012}$ and early marriage tends to greatly reduce girls' access to formal education, thereby limiting their literacy skills and future earning potential. ${ }^{29-31}$

Increased child marriage during conflict and displacement is not unique to the Syrian crisis. Prior evidence suggests that vulnerability to early marriage can be exacerbated by armed conflict ${ }^{32-35}$ and natural disasters. ${ }^{22}$ Earlier work on issues of child protection in Lebanon identified economic desperation as an important factor underlying why early marriage was becoming more prevalent and why children were being married at younger ages. ${ }^{8}$ As financial reserves become depleted, some families find themselves unable to meet the basic needs of all family members and make the choice to marry adolescent girls earlier than they would have otherwise.
Additionally, in conflict settings the risk of sexual violence and harassment is often heightened and some families feel that marriage and a good husband will offer the girl protection over and above that which her father or other male guardians can provide. ${ }^{8} 146$ Furthermore, in some societies, girls who have experienced sexual violence are considered unsuitable for marriage, which can bring dishonour to her and her family. By arranging early marriages, some families believe they are reducing or eliminating this risk.

There is less research about the factors that contribute to child marriage in the context of humanitarian settings and forced displacement. Undoubtedly, gender inequalities continue to be an important determinant of when girls marry and recent qualitative research on child marriage among Syrian refugees highlights the importance of insecurity as well as economic need and disruption of educational opportunities. ${ }^{37}$ However, there is little quantitative or mixed methods data about the factors that influence age of marriage in humanitarian settings. This study was designed to help address this knowledge gap by using a mixed methods approach to identify new insights into the societal, economic, security, religious and psychosocial factors contributing to child marriage among Syrian refugees in Lebanon.

\section{METHODS \\ Study design and participants}

This cross-sectional, mixed qualitative-quantitative study was conducted in Lebanon by the ABAAD Resource Center for Gender Equality and Queen's University. Data were collected in July and August 2016.

Individuals had to be aged 13 years or older to be eligible for participation. A variety of participant subgroups were recruited to capture a wide range of perspectives on the lives of Syrian girls in Lebanon. These subgroups included married and unmarried Syrian girls, Syrian mothers and Syrian fathers as well as married and unmarried men. The married and unmarried men were included to capture the perspectives of those who may have married or may marry a Syrian girl and they were of Syrian, Lebanese or Palestinian nationality.

\section{Instrument}

SenseMaker is a mixed methods data collection tool that extracts meaning from a collection of stories that are shared about people's experiences. Assisted by a prompting question to elicit stories on a topic of interest (in this case the experiences of Syrian girls in Lebanon), participants tell and then quantitatively 'plot' their interpretation of the story using predefined questions on handheld tablets, smartphones or computers. SenseMaker then quantifies each of the plotted points, providing statistical data backed up by the explanatory narrative. ${ }^{38}$ The current research used SenseMaker as an innovative approach to provide new insights into the factors contributing to child marriage. 
Team members with collective expertise related to humanitarian crises, SGBV, child, early or forced marriage and survey design drafted the SenseMaker survey in collaboration with an experienced SenseMaker consultant. Choosing one of three open-ended prompting questions, participants were asked to share an anonymous story about the experiences of Syrian girls in Lebanon. The SenseMaker survey intentionally did not ask direct questions about child, early or forced marriage. This was to avoid introducing reporting biases that are inherent if the field of enquiry is narrowed to a research hypotheses ${ }^{39}$ and to allow stories about child marriage to emerge from the broader landscape of experiences thus situating them in the everyday lives of Syrian girls. After sharing a story, participants were asked to interpret the experiences by plotting their perspective between three variables (triads), using sliders (dyads) or plotting their perspectives on a graph (stones). For the purposes of the survey, Syrian girls were defined as females below the age of 18. Multiple-choice questions collected demographic information and contextualised the shared story (eg, emotional tone of the story, how often do the events in story happen, who was the story about, etc). The survey was drafted in English, translated to Arabic by a Syrian translator and then back translated to English to check for accuracy. Translation discrepancies were resolved by consensus. The survey was initially piloted in Lebanon among 28 participants and revisions were made based on survey responses as well as feedback on question clarity, reported difficulty and survey length.

\section{Procedure}

The data collection team consisted of 12 interviewers chosen based on their place of residence, gender, nationality and prior relevant work experience. Six of the interviewers were Syrian females, purposively selected to interview Syrian girls and mothers, three of the interviewers were Syrian men to interview male Syrian participants and three were Lebanese men to interview male Lebanese participants. Interviews were conducted in three locations: the greater Beirut area, Tripoli and Beqaa. Within each purposively selected participant subgroup, a convenience sample was used. All interviewers participated in a 4-day training session prior to initiation of data collection. For each of the three locations, an ABAAD field staff member oversaw data collection.

Interviewers introduced the study to potential participants using a predefined script. If the individual expressed interest in participating, the interviewer and participant choose a private location out of earshot of others. All interviews were conducted in Arabic. Shared stories were audio-recorded. On completion of the first story and follow-up questions, all participants were asked if they would like to share a second story and therefore the number of shared stories exceeds the number of unique participants. Data were collected using the SenseMaker app ${ }^{40}$ on iPad Mini 4s and was uploaded to Cognitive Edge's secure server at the end of each interview day.
Additional details of the study's implementation have been previously published. ${ }^{41}$

\section{Ethical approval}

All interviews were conducted confidentially and no identifying information was recorded. Informed consent was reviewed in Arabic and ascertained by study participants tapping a consent box on the handheld tablet. Since the study involved minimal risk written consent was waived. No monetary or other compensation was offered.

\section{Statistical analysis}

SenseMaker's quantitative data are generated when participants plot their responses to the self-interpretation questions (ie, dyads, triads and stones). The collective plots are then examined to identify patterns of perspectives on particular issues. ${ }^{40}{ }^{42}$ SenseMaker data were exported to Tableau V.10.1.5 ${ }^{43}$ and overall response patterns for dyads, triads and stones were examined visually. Statistical tests were run on those questions that appeared to have potential differences based on visual inspection. Dyad results are presented as histograms representing the spectrum of possible responses from one extreme to the other. For analytical purposes, the three bars at either end of the histogram were combined and taken to represent the most extreme responses. Using SPSS (IBM SPSS Statistics V.24.0.0.0), ${ }^{44}$ dyad responses were analysed using the Kruskal-Wallis $\mathrm{H}$ test with a $\mathrm{X}^{2}$ test statistic to determine if the bar areas were statistically different between groups. ${ }^{45} 46$ A post hoc analysis using Fisher's least squares difference was conducted to identify which groups differed. A P value of $<0.05$ was used to determine statistically significant differences. For the triad data, geographic means for each group were compared to identify statistically significant differences in response patterns. ${ }^{47}{ }^{48}$ Using R scripts (R V.3.4.0) ${ }^{49} 95 \%$ CIs were generated for the geometric mean of each subgroup and are represented visually as confidence ellipses around the geometric means. ${ }^{50}$ If the $95 \%$ confidence ellipse for a given mean did not overlap other $95 \%$ confidence ellipses, the geometric mean for that group was taken to be statistically different. For the stone questions, results are presented as the X-coordinate and Y-coordinate for the arithmetic mean of each group. Statistical differences between groups were determined with the Kruskal-Wallis $\mathrm{H}$ test and Fisher's least squares difference. Once patterns of perspectives were identified in the quantitative data, the accompanying narratives were reviewed to facilitate interpretation of the quantitative results. The current analysis includes only those stories that were about or mentioned child marriage.

\section{RESULTS}

\section{Study participants}

A total of 1422 self-interpreted stories about the experiences of Syrian girls in Lebanon were collected in July and August 2016 from 1346 unique individuals representing a variety of different participant groups. 
Full demographics of study participants are provided in table 1. All presented results are exclusively from participants whose stories were about $(\mathrm{n}=332(23 \%))$ or mentioned $(\mathrm{n}=245(17 \%))$ child marriage. Provided sample sizes represent the number of responses on each individual question.

\section{Dyads}

The dyad questions asked participants to interpret the experiences of the girls in their stories between two extremes on a variety of perspectives including protection (figure 1). A Kruskal-Wallis $\mathrm{H}$ test showed a statistically significant difference in patterns of response between the different groups, $\chi^{2}=29.606, \mathrm{P}<0.001$. In post hoc analysis, the response pattern for married girls, unmarried girls and Syrian mothers differed from that of Syrian fathers, married men and unmarried men (all $\mathrm{P}$ values $<0.001$ ) with married girls, unmarried girls and mothers being more likely to report that girls were protected too much. A list of other dyad questions is included in table 2.

Stories shared by female participants provided some perspective on the perception that Syrian girls were overprotected. One girl shared her personal story about being marrying quickly after she was sexually harassed and reported that she was protected too much in this context:

I was 12 years old when we were displaced to Lebanon. After we arrived, I was sexually harassed by an older man. When my parents found out about this, they forced me to get married. Now, I have a child, and I am pregnant. I am so unhappy.

Other female participants talked about early marriage as a means of protection. For example, a Syrian mother spoke of marriage as a way to protect her daughter from sexual harassment and/orviolence and reported that the girl in the story (ie, her daughter) was protected too much:

In Syria, my daughter was 11 years old, and she went to school... Here, we couldn't enroll her into any school. We were compelled to marry her after a man proposed to marry her. She has a child now. I am aware that her situation could have been better... We wanted her to be educated, but our circumstances were overwhelming. We favored marrying her to a decent man; this is better than waiting for an unwanted act/thing to happen to her.

In contrast, men were more likely to report that Syrian girls were not protected enough. However, stories shared by men again illustrated the risks faced by girls in Lebanon. A Syrian father shared the following story and reported that the girl in the story was not protected enough:

The guys kidnapped her, raped her and forced her to get married to one of them... The mother and the girl had to move to another area and the mother stopped working because she was afraid of leaving her daughter alone. The girl was scared to even go out of the house... The family had a lot of rent to pay, so the mother eventually married her daughter to a 60 year old man, in order to protect her and to decrease her living expenses.

A married male participant talked about a Syrian girl marrying outside her sect due to financial need and reported that the girl in the story was not protected enough:

In Lebanon, they were vulnerable, so the girls had to stop school and work... The girl had a marriage proposal but from a guy of another sect. Due to their financial status and poverty she had to marry him, because he had a good financial status. After a while, she delivered a baby girl, her husband left her and the baby... and he never recognized his wife nor his daughter. The girl had to return back to working and return to the humiliation and poverty she faced before.

\section{Triads}

The triad questions asked participants to interpret the experiences of girls in their stories in relation to three predetermined labels on a triangle. All triad questions are listed in table 2. In the example provided in figure 2, participants were asked what their shared stories were mainly about. Each data point represents the geometric mean for that group with the $95 \%$ confidence ellipse surrounding it. The geometric mean for unmarried girls differed from all other groups as demonstrated by its non-overlapping 95\% confidence ellipse. The geometric means for married and unmarried men were nearly identical and were also distinct from all other groups.

Unmarried girls were more likely to interpret their stories as being about some combination of education, protection/security and financial resources. For instance, one unmarried girl provided the following story, interpreting it as being about an equal mix of education, protection/security and financial security :

The father forced [his 16year old daughter] to get married to an older man who doesn't like his work; he drinks and he used to beat her up a lot. This is why she got divorced and went back to her parents' house. This man (father) did not let any of his daughters go to school... He used to wake them up at 2 am to go with the sergeant to collect potatoes. He was too greedy, he didn't care about his daughters, he only cared about the salary his daughters brought home. He took the money from his daughters and went to Beirut to have fun... Their ages were between 9 and 16 years.

Married and unmarried men, in contrast, were more likely to interpret their stories as being about financial security and/or protection but were less likely to indicate that their stories were about education. There were a notable number of stories about girls engaged in transactional sex and girls being exploited to help with their families' extreme poverty. For example, a married Syrian man shared the following story, which he interpreted as being primarily about financial security:

I know a Syrian family that was displaced to Lebanon. They have three daughters. When one of their daughters was 16 years old, she was compelled to work in sinful routes due to 
Table 1 Demographic characteristics of story narrators

\begin{tabular}{|c|c|c|c|}
\hline Characteristic & All respondents (n (\%)) & $\begin{array}{l}\text { Non-child marriage } \\
\text { respondents (n (\%)) }\end{array}$ & $\begin{array}{l}\text { Child marriage } \\
\text { respondents (n (\%)) }\end{array}$ \\
\hline Age of respondent (years) & $\mathrm{N}=1416$ & $N=843$ & $N=573$ \\
\hline $13-17$ & $312(21.9)$ & $177(20.9)$ & $135(23.4)$ \\
\hline $18-24$ & $335(23.6)$ & $198(23.4)$ & $137(23.7)$ \\
\hline $25-34$ & $432(30.4)$ & $251(29.7)$ & $181(31.4)$ \\
\hline $35-44$ & $203(14.3)$ & $133(15.7)$ & $70(12.1)$ \\
\hline $45-54$ & $96(6.8)$ & $60(7.1)$ & $36(6.2)$ \\
\hline $55-64$ & $34(2.4)$ & $21(2.5)$ & $13(2.3)$ \\
\hline$>65$ & $4(0.3)$ & $3(0.4)$ & $1(0.2)$ \\
\hline Sex & $\mathrm{N}=1420$ & $\mathrm{~N}=843$ & $N=577$ \\
\hline Male & $722(50.8)$ & 447 (52.9) & $275(47.7)$ \\
\hline Female & $698(49.1)$ & $396(46.9)$ & $302(52.3)$ \\
\hline Marital status & $\mathrm{N}=1400$ & $\mathrm{~N}=834$ & $\mathrm{~N}=566$ \\
\hline Married & $826(58.1)$ & $456(54.0)$ & $370(64.1)$ \\
\hline Single & $512(36.0)$ & $348(41.2)$ & $164(28.4)$ \\
\hline Divorced/separated & $37(2.6)$ & $15(1.8)$ & $22(3.8)$ \\
\hline Widowed & $25(n=1.8)$ & $15(1.8)$ & $10(1.7)$ \\
\hline Identifies as parent & $\mathrm{N}=1390$ & $\mathrm{~N}=830$ & $\mathrm{~N}=560$ \\
\hline Yes & $695(48.9)$ & $394(46.6)$ & $301(52.2)$ \\
\hline No & $695(48.9)$ & $436(51.6)$ & $259(44.9)$ \\
\hline Religion & $\mathrm{N}=1247$ & $\mathrm{~N}=721$ & $\mathrm{~N}=526$ \\
\hline Sunni & $1159(81.5)$ & $665(78.7)$ & $494(85.6)$ \\
\hline Shia & $26(1.8)$ & $18(2.1)$ & $8(1.4)$ \\
\hline Druze & $23(1.6)$ & $17(2.0)$ & $6(1.0)$ \\
\hline None & $22(1.5)$ & $11(1.3)$ & $11(1.9)$ \\
\hline Christian & $13(0.9)$ & $6(0.7)$ & $7(1.2)$ \\
\hline Other & $4(0.2)$ & $2(0.2)$ & 0 \\
\hline Home region & $\mathrm{N}=1414$ & $\mathrm{~N}=840$ & $\mathrm{~N}=577$ \\
\hline Lebanon & $305(21.4)$ & $204(24.1)$ & $101(17.5)$ \\
\hline Homs & $281(19.8)$ & $155(18.3)$ & $126(21.8)$ \\
\hline Damascus & $221(15.5)$ & $128(15.2)$ & $93(16.1)$ \\
\hline RifDimashq & $132(9.3)$ & $82(9.7)$ & $50(8.7)$ \\
\hline Aleppo & $118(8.3)$ & $67(7.9)$ & $51(8.8)$ \\
\hline Hama & $94(6.6)$ & $50(5.9)$ & $44(7.6)$ \\
\hline Idlib & $67(4.7)$ & $38(4.5)$ & $29(5.0)$ \\
\hline Daraa & $59(4.1)$ & $29(3.4)$ & $30(5.2)$ \\
\hline Other & $137(9.7)$ & $87(10.3)$ & $53(9.2)$ \\
\hline Location in Lebanon & $\mathrm{N}=1422$ & $\mathrm{~N}=845$ & $\mathrm{~N}=577$ \\
\hline Beqaa & 471 (33.1) & $252(29.8)$ & $219(38.0)$ \\
\hline Greater Beirut area & $467(32.8)$ & $301(35.6)$ & $166(28.8)$ \\
\hline Tripoli & $484(34.0)$ & $292(34.6)$ & $192(33.3)$ \\
\hline Time in Lebanon (years) & $\mathrm{N}=1411$ & $\mathrm{~N}=840$ & $\mathrm{~N}=571$ \\
\hline$<1$ & $82(5.8)$ & $52(6.2)$ & $30(5.2)$ \\
\hline $1-3$ & $284(20.0)$ & $161(19.1)$ & $123(21.3)$ \\
\hline $3-5$ & $617(43.4)$ & $347(41.1)$ & $270(46.8)$ \\
\hline
\end{tabular}




\begin{tabular}{lccc}
\hline Table $\mathbf{1}$ Continued & & & \\
\hline Characteristic & All respondents (n (\%)) & $\begin{array}{l}\text { Non-child marriage } \\
\text { respondents (n (\%)) }\end{array}$ & $\begin{array}{l}\text { Child marriage } \\
\text { respondents (n (\%)) }\end{array}$ \\
\hline $5-7$ & $81(5.7)$ & $51(6.0)$ & $30(5.2)$ \\
\hline$>7$ years & $347(24.4)$ & $229(27.1)$ & $118(20.5)$ \\
\hline Stories by subgroup & $\mathrm{N}=1422$ & $\mathrm{~N}=845$ & $\mathrm{~N}=577$ \\
\hline Married Syrian girls & $197(13.9)$ & $68(8.0)$ & $129(22.4)$ \\
\hline Unmarried Syrian girls & $230(16.2)$ & $161(19.1)$ & $69(12.0)$ \\
\hline Syrian mothers & $245(17.2)$ & $154(18.2)$ & $81(15.8)$ \\
\hline Syrian fathers & $198(13.9)$ & $118(14.0)$ & $95(13.9)$ \\
\hline Married men & $228(16.0)$ & $133(15.7)$ & $88(15.3)$ \\
Unmarried men & $268(18.8)$ & $180(21.3)$ & $25(4.3)$ \\
\hline Community leaders & $56(3.9)$ & $31(3.7)$ & \\
\hline
\end{tabular}

Demographic characteristics disaggregated by whether the shared stories were about or mentioned child marriage (child marriage respondents) or did not mention child marriage (non-child marriage respondents).

$\mathrm{n}$, number of shared stories.

the family's circumstances. She got raped, and she worked in prostitution. Now, she is a drug addict, and she is 18 years old.

An unmarried Syrian man also interpreted the following story as being about financial security:

I know a girl who displaced from Sham to Lebanon. She wanted to continue her education, but she was surprised with the situation here. The public schools are not good, and the other schools are very expensive. She wasn't able to go back to school. So, her parents wed her to get some money. This is the situation of most Syrian families. They are selling their daughters.

The triad shown in figure 3 asked participants why the events in the story occurred. The geometric means for married and unmarried men differed from all other

From your perspective, the Syrian girl(s) in your story was/were...

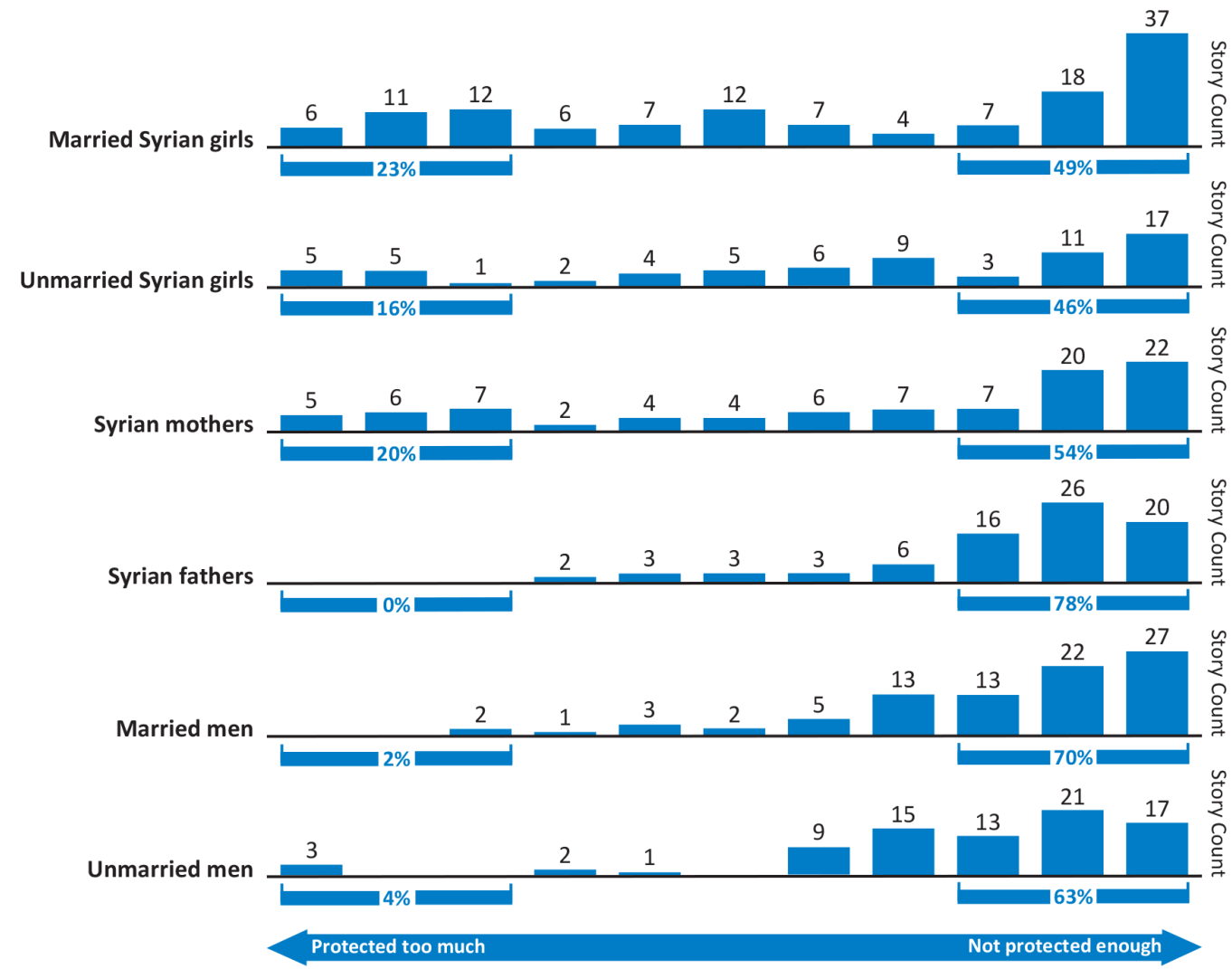

Figure 1 Dyad regarding protection of the Syrian girl(s) in the shared story $(n=533)$. 
Table 2 Survey questions with possible responses

Question
Dyads

*In the story, the Syrian girl(s) was/were...

${ }^{\star}$ From your perspective, the Syrian girl (s) in your story was/ were..

\section{Possible responses}

The events in the story were...

In the story shared, it is more important for Syrian girls to...: 1) Adapt to their new circumstances; 2) maintain their Syrian identity or some combination thereof

\section{Triads}

*The shared story mostly relates to:

1) Education; 2) protection and security; 3) financial resources or some combination thereof

Thinking about the story shared, what helps support Syrian girls in Lebanon?

*The events in the story happened mostly because of...:

1) Programmes and services; 2) family and friends; 3) cultural environment and religious values or some combination thereof

1) Safety; 2) expectations of the community; 3) financial resources or some combination thereof

Based on the experiences shared, what is needed to improve life for Syrian girls in Lebanon:

1) Programmes and services; 2) girls need to be respected; 3) need the basic necessities to survive or some combination thereof

If the girl in your story had the freedom to choose, in your opinion, what would she prefer to have for her future:

1) Marriage and having her own children; 2) financial security; 3) education or some combination thereof

Stones

Y-axis=importance for girls (low to high)

$\mathrm{X}$-axis=importance for parents (low to high)

1) *Education for girls; 2) *finding a suitable husband; 3)

*safety; 4) *maintaining family honour; 5) employment for girls; 6) rights of girls and/or 7) *happiness

Y-axis=financial security (low to high)

$\mathrm{X}$-axis=ability to offer protection (low to high)
1) *Sending girls to school regularly; 2) girls getting married;

3) girls joining the workforce and/or 4) girls staying at parents' home

Response was optional for all questions. Data from questions in italics were analysed statistically based on visual inspection of response patterns.

${ }^{\star}$ At least one difference in response pattern was statistically significant between participant groups.

groups and they were more likely to share a story about financial resources.

Married girls, unmarried girls and mothers were more likely to perceive the events in their stories as resulting from a combination of safety, financial resources and expectations of the community. For instance, the following married girl responded to the triad almost directly in the middle, giving equal weight to all three options:

I got married at the age of 14 because my parents feared for my safety. There was a lot of kidnapping in our village... Now I have marital problems... I advise parents to reject the idea of early marriage. It is not right. The girl should be allowed to live through her whole childhood. I will not approve of my daughters getting married at an early age; especially after my own experience.

This Syrian mother spoke about concerns for girls' safety and education in Lebanon:

Parents fear for their safety here, therefore they are marrying them off very early. The parents are not thoroughly investigating the situation of their 'husband to be'; they don't care. They only want to marry their daughters... I know more than one case where the husband ran off to Syria after his wife got pregnant, and he never came back. Syrian girls are going through very tough circumstances.

Married and unmarried men were more likely to report that financial security was primarily responsible for events in their shared stories. An unmarried Syrian man reported that the events in the following story had occurred primarily because of financial security:

I know a family who has two daughters and a son. He couldn't enroll them in school, so he forced one daughter to work. But he forced his other daughter to get married more than one time and to get a divorce after every marriage in order to collect her dowry. She'll be married for seven days maximum, and then she'll get a divorced. I know her brother, and he told me that his sister is 17 years old. Since their financial situation is terrible, the father forces his daughter to do so. It is a way to get money. 


\section{The shared story mostly relates to ...}

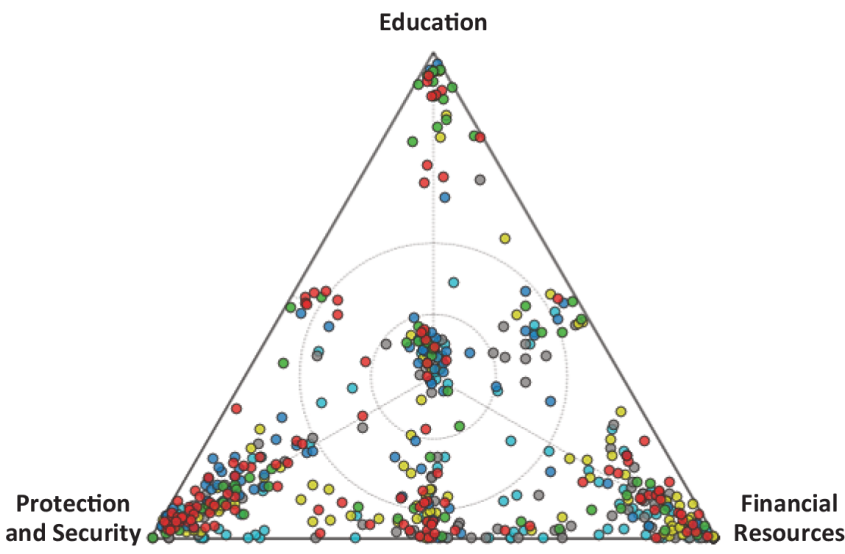

Married Syrian girls

Unmarried Syrian girls

Syrian mothers

Syrian fathers

Married men

Onmarried men

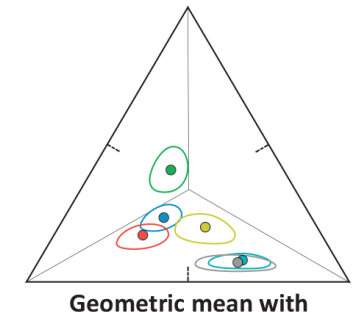

$95 \%$ confidence ellipse for each group

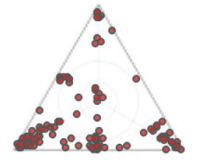

Married

Syrian girls
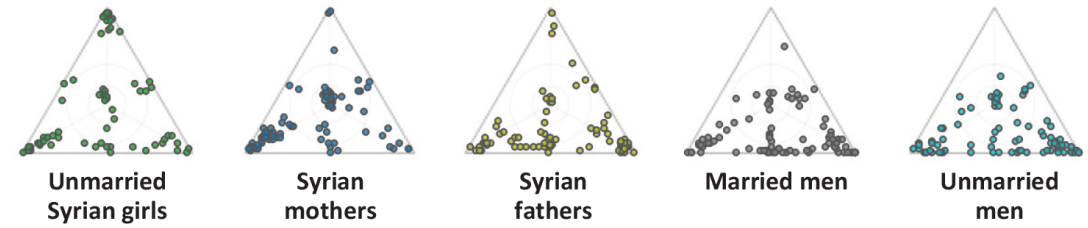

Figure 2 Triad regarding main topic of the shared story $(n=523)$ with geometric means and $95 \%$ confidence ellipses for each group.

\section{Stones}

In the stone questions, participants plotted a variety of topics on a grid as they related to the events in their shared stories. Table 2 lists the stone questions included in survey. In the example provided in figure 4, the importance of finding a suitable husband was plotted and each data point represents X-coordinate and Y-coordinate for the arithmetic mean of that group. The arithmetic mean for married Syrian girls was statistically different from the arithmetic means for unmarried girls

\section{The events in the story happened mostly because of ...}
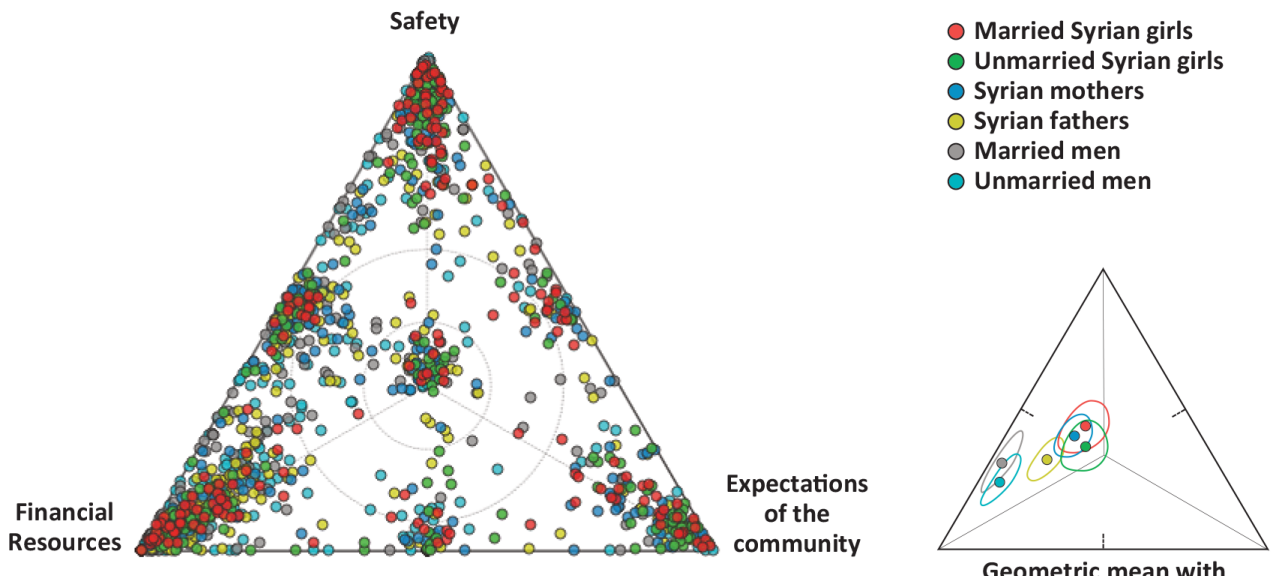

$95 \%$ confidence ellipse for each group

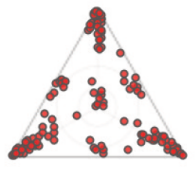

Married Syrian girls

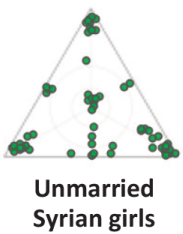

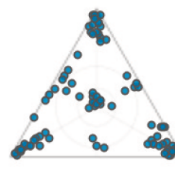

Syrian mothers

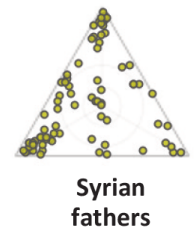

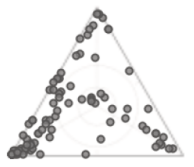

Married men

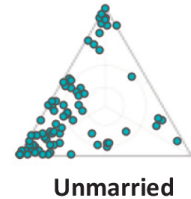

men

Figure 3 Triad regarding why events in the story happened $(n=535)$ with geometric means and $95 \%$ confidence ellipses for each group. 
Finding suitable husband

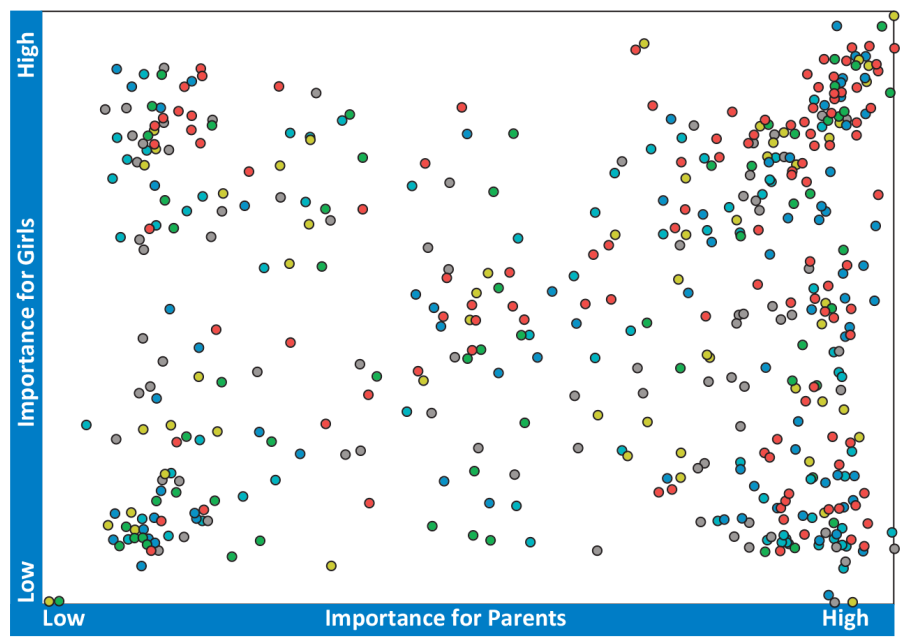

Married Syrian girls

- Unmarried Syrian girls

- Syrian mothers

O Syrian fathers

O Married men

O Unmarried men

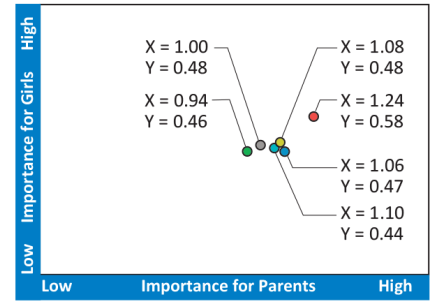

Arthrimetic mean for each group

Figure 4 Finding suitable husband stone $(n=175)$ with $X$-coordinate and Y- coordinate for the arithmetic mean for each group.

$(\mathrm{P}<0.001$ for $\mathrm{X}$-coordinate and 0.001 for Y-coordinate), married men $(\mathrm{P}=0.001$ for $\mathrm{X}$-coordinate and 0.003 for Y-coordinate) and unmarried men ( $\mathrm{P}=0.01$ for $\mathrm{X}$-coordinate and 0.001 for Y-coordinate).

Married Syrian girls were more likely to report that finding a suitable husband was of high importance for themselves as well as their parents. For instance, one married girl who shared a story about herself, rated finding a suitable husband as being very important to both her and her parents:

I was married when I was 17 years old, and I have a child. I met my husband in (Sabra). We got to know each other for a week only, and then we got married. We have been going through a lot of marital problems... My sisters, 14 and 15 years old, were forced by my parents to get married. Our parents imprisoned us at home; we were not allowed to go out. I wanted to get married in order to run away from my parents' treatment, but marriage was even worse.

In contrast, a young, unmarried female participant reported that finding a suitable husband was unimportant for both girls and parents:

My dad's health was deteriorating and my cousin proposed to me, so my dad agreed because he was worried about me and wanted to know that someone would take care of me if he passed away. I was around 12 or even younger. I agreed but I don't know why I made this decision, I was not aware enough. So I got engaged. After a while my dad passed away, and problems started occurring between me and my fiancé. So I decided to leave him, and continue my education and secure my future. It will be a weapon in my hand in the future.

Married and unmarried men were also more likely to report that finding a suitable husband was of lower importance to girls and to parents. This married Lebanese man reported the following story and interpreted it as such:

I met a Syrian guy... he started telling me about his circumstances. He wanted to get his 15 year-old girl married just to decrease the burden... His daughter is still 15 years old. She is not educated and doesn't know anything about marriage, and he wants to get her married just to decrease his expenses.

\section{DISCUSSION}

Using Cognitive Edge's SenseMaker, 1422 self-interpreted narratives about the experiences of displaced Syrian girls in Lebanon were collected from 1346 unique participants. Stories and personal interpretations of narratives from married and unmarried girls, mothers and fathers and married and unmarried men were included. Respondents independently identified child marriage as an important issue in their community with a large proportion of stories being about or mentioning child marriage despite no prompting about the topic in the study introduction or questions.

Findings about the root causes of child marriage among Syrian refugee communities in Lebanon are consistent with existing research from other contexts in so far as poverty, lack of access to education, fear of SGBV and unstable political situations are causal factors in increased prevalence of early age at marriage. ${ }^{31-34}$ What this study offers by way of new knowledge, is the disaggregated opinions between groups and important gender differences in understanding girls' vulnerability, and the causal associations, related to early marriage. Men were more likely to stress financial resources and commonly discussed child marriage as a financial coping strategy. Women and girls, in contrast, were more likely to identify their stories as being about protection/security as well as education and more often saw child marriage as a way to protect girls from SBGV and harassment. Similarly, the interpretations of protection varied significantly between men and women. Female participants were more likely to view young girls as being 'protected too much', while men more often perceived girls to be 'not protected enough'. Despite these different perspectives, our research shows 
that both men and women viewed child marriage as a negative reality and acknowledged the negative impacts it has on the lives of young girls. Like other members of the family (including the girls themselves), fathers often viewed early marriage as a response to unfavourable economic conditions and safety concerns in the community. ${ }^{29} 3034$

The current work also provides new insights into circumstances that lead some girls to purposefully choose early marriage. In many cases, girls deciding to marry early described a lack of freedom at home and not being able to go outside or to have a social life, largely because parents feared for their safety. These girls often presented early marriage as a 'way out' of an unfavourable home situation. In some cases, girls seemed to appreciate that there were inherent risks in marrying a man they did not know but they were willing to take that risk. The parents' safety concerns typically centred on preserving the honour of girls by limiting their exposure to sexual experiences before marriage as well as SGBV and there was a clear sense that the risks were higher in Lebanon than they had been in Syria. The sense of social isolation among displaced Syrian girls speaks to the importance of safe spaces in humanitarian settings, where girls can build social networks, receive support and interact with peers without the risk of violence and the stress associated with perceived risks of violence. ${ }^{51}$ Safe spaces may also serve as an appropriate venue to introduce life-skills training, vocational training and much-needed education on sexual and reproductive health. In order for girls' safe spaces to be useful, however, they will need to be recognised by the girl and her family as truly safe and there will need to be safe modes of transportation to and from.

Our data also highlight a sense of urgency to marry Syrian girls quickly in Lebanon. Shared narratives noted that girls were being married after only knowing the groom for a very short time, if at all. Again, this seemed to represent a distinct change from marriage practices in Syria where potential grooms and their families were more often vetted to ensure that he would be a suitable husband. The urgency to marry girls quickly likely stems from a strong desire to protect them as well as from economic need, and it was noteworthy that the grooms were sometimes chosen because of their financial status. However, this practice may ultimately be placing girls at greater risk for intimate partner violence (IPV) as the data illustrate how girls were sometimes married to unknown but well-off men, only to find themselves in abusive marriages or to be later abandoned with the responsibility of caring for their children alone.

The exploitation of girls described in this dataset, including transactional sex and short-term contractual marriages, is also a cause for great concern. It is noteworthy that men were more likely to talk about sexual exploitation and they were more likely to talk about it candidly, particularly married and unmarried men (Syrian and Lebanese). In a few described cases, girls were repeatedly being married for brief periods of time in exchange for money paid to their families. These girls typically have little autonomy over their sexual and reproductive health and the associated risks, including complicated labour and delivery at a young age, inadequate childbirth spacing, sexually transmitted infections and HIV/AIDS, are significant and in many cases, long lasting. Similar short-term marriages have also been reported in other countries where it is sometimes labelled 'marriage tourism' or 'summer marriage' often in reference to Arab men coming to marry girls for a short period of time..$^{52-56}$ There is an urgent need to address the sexual exploitation of girls and to prioritise access to medical care to mitigate the sexual and reproductive health consequences.

Although broad engagement at the community level is required for meaningful and sustained progress towards addressing child marriage, our analysis suggests that it may be more effective to tailor interventions differently for men and women in gender-sensitive approaches. For instance, strategies to address child marriage targeted towards mothers might focus on providing safe and suitable schooling as well as improved security for girls in the community (eg, ensuring that girls can commute to/from school safely). It is also important that education for girls be framed as a way of increasing future financial stability for the girls themselves, and for their families as this might resonate more with fathers. Strategies to address child marriage among fathers might focus on economic empowerment or skills training to provide financial stability for the family in addition to raising awareness about the principles of child protection.

This study has several limitations. First, despite considerable effort to collect narratives from as wide a range of participants as possible, the sample was not representative and thus the results are not generalisable. More marginalised or mobile families may have been under-represented and girls less than age 13 were not included. Second, SenseMaker narratives are relatively short in comparison to more traditional qualitative interviews, and the shared stories may lack the detail and richness afforded by in-depth interviews. Finally, participants' interpretation of their shared stories may have been constrained by the predetermined labels on the dyads, triads and stones, although review of the narratives shows that the chosen labels were highly relevant to many of the shared experiences. There are also several notable strengths including a relatively large sample size with 1422 self-interpreted narratives providing a wide range of perspectives from Syrian girls and their parents as well as married and unmarried men in the community. Using a mixed methods approach allowed for new insights into child marriage in this context and the self-interpretation by participants minimised inherent researcher biases. Additionally, the lack of direct questioning about child, early or forced marriage allowed the child marriage narrative to emerge from the broader landscape of 
experiences and contextualised child marriage in the everyday lives of Syrian families.

\section{CONCLUSIONS}

This study reveals a complex myriad of factors that contribute to early marriage after forced displacement including financial hardships, lack of educational opportunities and the increased vulnerability of refugee girls to SGBV and harassment. Displaced communities may resort to negative coping mechanisms such as child marriage as a means to alleviate financial burdens and preserve their families' safety and honour. In some cases, girls are being sexually exploited under the guise of short-term contractual marriages, which puts their health at risk while offering them and their children little to no protection.

Sustainable Development Goal 5.3 calls for the elimination of child, early and forced marriage by 2030 and based on the current analysis, gender-specific strategies to address child marriage might be more effective in reaching this goal. These approaches should be responsive to the gendered needs and concerns of all community members, while focusing on the importance of engaging men and boys.

Acknowledgements The authors are indebted to all participants who shared their stories and perspectives. The authors are grateful to Ghida Anani and team members from the ABAAD Resource Center for Gender Equality including team leads Katia Ghandoura, Clara El Warrak and Salma Atwi. The authors would also like to thank the interviewers as well as Laurie Webster (QED Insight) for their dedication and hard work. This research would not have been possible without the financial support of the Sexual Violence Research Initiative and the World Bank Group's Development Marketplace for Innovation on GBV Prevention (in Memory of Hannah Graham). SenseMaker is a registered trademark of Cognitive Edge.

Contributors $S A B, C D, S M$ and $A B$ conceived of the study idea. $S A B$ designed the survey with input from $N B, A B, C D, S G$ and $S M$. NB, CD, SM and SAB conducted the pilot testing. SM and LK directed field implementation and oversaw recruitment of interviewers and team leads. NB, SAB and CD designed interviewer training with $\mathrm{SM}, \mathrm{SAB}$ and $\mathrm{SG}$ leading the training. SR, HB and NB assisted in quality control during data collection. Analysis was done by SAB. SAB drafted the initial manuscript with all authors contributing to writing. All authors read and approved the final manuscript.

Funding Sexual Violence Research Initiative and the World Bank Group's Development Marketplace for innovation on GBV prevention (in Memory of Hannah Graham)

\section{Competing interests None declared.}

Ethics approval Queen's University Health Sciences and Affiliated Teaching Hospitals Research Ethics Board.

Provenance and peer review Not commissioned; externally peer reviewed.

Data sharing statement Data available by request to authors

Open Access This is an Open Access article distributed in accordance with the Creative Commons Attribution Non Commercial (CC BY-NC 4.0) license, which permits others to distribute, remix, adapt, build upon this work non-commercially, and license their derivative works on different terms, provided the original work is properly cited and the use is non-commercial. See: http://creativecommons.org/ licenses/by-nc/4.0/

(c) Article author(s) (or their employer(s) unless otherwise stated in the text of the article) 2018. All rights reserved. No commercial use is permitted unless otherwise expressly granted.

\section{REFERENCES}

1. UNHCR. UNHCR - Syria conflict at 5 years: the biggest refugee and displacement crisis of our time demands a huge surge in solidarity
[Internet]: UNHCR, 2016. http://www.unhcr.org/afr/news/press/2016/ 3/56e6e3249/syria-conflict-5-years-biggest-refugee-displacementcrisis-time-demands.html (cited 15 May 2017).

2. Human Rights Watch. Syrian country summary 2016 [Internet]: Human Rights Watch, 2017. https://www.hrw.org/sites/default/files/ syria_1.pdf (cited 16 May 2017).

3. UNICEF. Hitting rock bottom: How 2016 became the worst year for Syria's children [Internet]: UNICEF, 2016. http://childrenofsyria.info/ wp-content/uploads/2017/03/SYRIA6-12March17.pdf (cited 16 May 2017)

4. Human Rights Watch. Lebanon: 250,000 Syrian children out of school [Internet]: Human Rights Watch, 2016. https://www.hrw.org/ news/2016/07/19/lebanon-250000-syrian-children-out-school (cited 17 Jul 2017).

5. Child Protection Working Group. Syria child protection assessment 2013 [Internet]. 2013. http://www.crin.org/en/docs/SCPA-FULL_ Report-LIGHT.pdf (cited 15 May 2017).

6. World Vision International. Robbed of childhood, running from war [Internet]. 2012. http://www.wvi.org/sites/default/files/Running from War FINAL UPDATED.pdf (cited 15 May 2017).

7. Bartels S, Hamill K. FXB Center for Health and Human Rights. Running out of time: survival of syrian refugee children in lebanon [Internet]. 2014. http://fxb.harvard.edu/fxb-report-survival-syrianrefugee-children-lebanon/ (cited 07 Dec 2015).

8. UNICEF. Under Siege: The devastating impact on children of three years of conflict in Syria [Internet]. 2014. http://www.unicef.org/ publications/index_72815.html (cited 07 Dec 2015).

9. Abu S. Amnesty International. Early Marriage and harrassment of Syrian refugee women and girls in Jordan [Internet]. 2013. https:// www.amnesty.org/en/latest/campaigns/2013/09/early-marriage-andharassment-of-syrian-refugee-women-and-girls-in-jordan/ (cited 13 Aug 2016)

10. UN Women. Inter-agency AssGender-based Violence and child protection among Syrian refugees in Jordan, with a focus on early marriage [Internet]. 2013:92 http://www.unwomen.org/-/media/ headquarters/attachments/sections/library/publications/2013/7/ report-web pdf.pdf?vs=1458 (cited 15 May 2017).

11. International Rescue Committee. Are we listening? acting on our commitments to women and girls affected by the Syrian conflict [Internet]. 2015. https://www.rescue.org/sites/default/files/ resource-file/IRC_WomenInSyria_Report_WEB.pdf (cited 20 Jun 2016).

12. Save the Children Fund. Too Young to Wed- The growing problem of child marriage among Syrian girls in Jordan. 2014. http:// www.savethechildren.org/atf/cf/\%7B9def2ebe-10ae-432c-9bd0df91d2eba74a\%7D/TOO_YOUNG_TO WED_REPORT_0714.PDF (cited 01 Dec 2016)

13. UNICEF. A Study on Early arriage in Jordan 2014 [Internet]. 2014. https://www.unicef.org/mena/UNICEFJordan_EarlyMarria geStudy2014(1).pdf (cited 1 Jun 2017)

14. Spencer D for Cl. "TO PROTECT HER HONOUR" Child marriage in emergencies - the fatal confusion between protecting girls and sexual violence [Internet]. http://insights.careinternational.org.uk/ publications/to-protect-her-honour-child-marriage-in-emergenciesthe-fatal-confusion-between-protecting-girls-and-sexual-violence (cited 07 Dec 2015).

15. UNFPA. New study finds child marriage rising among most vulnerable Syrian refugees [Internet]: UNFPA, 2017. http://www. unfpa.org/news/new-study-finds-child-marriage-rising-among-mostvulnerable-syrian-refugees. (cited 08 Jun 2017).

16. UNICEF. Child marriage: child protection from violence, exploitation and abuse | UNICEF [Internet]: UNICEF, 2016. https://www.unicef. org/protection/57929_58008.html. (cited 15 May 2017).

17. Sexual Rights Initiative. Analysis of the language of child early and forced marriages [Internet]. 2013. http://www.sexualrightsinitiative. $\mathrm{com} / \mathrm{wp}$-content/uploads/SRI-Analysis-of-the-Language-of-ChildEarly-and-Forced-Marriages-Sep2013.pdf (cited 2 Aug 2017).

18. United Nations. Universal declaration of human rights | United Nations [Internet]: United Nations High Commissioner for Refugees. http://www.un.org/en/universal-declaration-human-rights/. (cited 21 Nov 2016).

19. UN Office of the high commissioner for human rights. Convention on the Rights of the Child [Internet]: United Nations. http://www.ohchr. org/en/professionalinterest/pages/crc.aspx. (cited 21 Nov 2016).

20. UN Office of the High Commissioner for Human Rights. Convention on consent to marriage, minimum age for marriage [Internet]: United Nations. http://www.ohchr.org/EN/Professionallnterest/Pages/ MinimumAgeForMarriage.aspx. (cited 21 Nov 2016).

21. UN Women. Convention on the elimination of all forms of discrimination against women [Internet: United Nations. http://www. un.org/womenwatch/daw/cedaw/. (cited 21 Nov 2016). 
22. United Nations Population Fund. Marrying too young: end child marriage [Internet]. 2012:1-76 https://www.unfpa.org/webdav/site/ global/shared/documents/publications/2012/MarryingTooYoung.pdf (cited 07 Dec 2015).

23. Girls Not Brides. Child marriage around the world [Internet]: Girls Not Brides, 2017. http://www.girlsnotbrides.org/where-does-it-happen/. (cited 01 Jun 2017).

24. Glinski A, Sexton M, Meyes L. The child, early and forced marriage resource guide task order, [Internet]: Banyan Global, 2015. https:// www.usaid.gov/sites/default/files/documents/1865/USAID_CEFM_ Resource-Guide.PDF (cited 16 May 2017).

25. Bunting A. Stages of Development: Marriage of Girls and Teens as an International Human Rights Issue. Soc Leg Stud 2005;14:17-38.

26. Ganchimeg T, Ota E, Morisaki N, et al. Pregnancy and childbirth outcomes among adolescent mothers: a World Health Organization multicountry study. BJOG 2014;121 Suppl 1(s1):40-8.

27. Raj $A$. When the mother is a child: the impact of child marriage on the health and human rights of girls. Arch Dis Child 2010;95:931-5.

28. Nove A, Matthews Z, Neal S, et al. Articles Maternal mortality in adolescents compared with women of other ages: evidence from 144 countries. 2014. https://ac.els-cdn.com/S2214109X13 701797/1-s2.0-S2214109X13701797-main.pdf?_tid=b1010 fba-d5fb-11e7-b3dc-00000aab0f6c\&acdnat $=15120664448$ 867e8a194e3faa3e1d91661fd250414 (cited 30 Nov 2017).

29. Nguyen MC, Wodon Q. Impact of child marriage on literacy and education attainment in Africa [Internet]: World Bank for the Global Partnership for Education, 2014. http://allinschool.org/wp-content/ uploads/2015/02/OOSC-2014-QW-Child-Marriage-final.pdf (cited 17 Jul 2017).

30. Chaaban J, Cunningham W. Measuring the Economic Gain of Investing in Girls The Girl Effect Dividend [Internet: The World Bank Human Development Network Children \& Youth Unit and the Poverty Reduction and Economic Management Network Gender Unit, 2011. http://documents.worldbank.org/curated/en/730721468326167343/ pdf/WPS5753.pdf (cited 17 Jul 2017).

31. Parsons J, Edmeades J, Kes A, et al. Economic Impacts of Child Marriage: A Review of the Literature. Rev Faith Int Aff 2015;13:12-22.

32. Schlecht J. Women's refugee commission: a girl no more: the changing norms of child marriage in conflict [Internet]. 2016. http:// reliefweb.int/sites/reliefweb.int/files/resources/Changing-Norms-ofChild-Marriage-in-Conflict.pdf (cited 19 Jul 2016).

33. ABAAD, Arab Institute for Human Rights. Regional seminar on child marriage during democratic transition and armed conflicts [Internet]. 2015. http://www. girlsnotbrides.org/resource-centre/regionalseminar-on-child-marriage-during-democratic-transition-and-armedconflict/ (cited 08 Jul 2017).

34. Neal S, Stone N, Ingham R. The impact of armed conflict on adolescent transitions: a systematic review of quantitative research on age of sexual debut, first marriage and first birth in young women under the age of 20 years. BMC Public Health 2016;16:1-11.

35. Schlecht J, Rowley E, Babirye J. Early relationships and marriage in conflict and post-conflict settings: vulnerability of youth in Uganda. Reprod Health Matters 2013;21:234-42.

36. Amnesty International Canada. Early marriage and harassment of Syrian refugee women and girls in Jordan [Internet]: Amnesty Canada Blog, 2013. http://www.amnesty.ca/blog/early-marriageand-harassment-of-syrian-refugee-women-and-girls-in-jordan (cited 15 May 2017)

37. Mourtada R, Schlecht J, DeJong J. A qualitative study exploring child marriage practices among Syrian conflict-affected populations in Lebanon. Confl Health 2017;11 https://link.springer.com/content/ pdf/10.1186\%2Fs13031-017-0131-z.pdf

38. SenseGuide. What is SenseMaker [Internet]. 2016. https:// senseguide.nl/what-is-sensemaker/ (cited 2 Aug 2017).

39. Cognitive Edge. Prompting question design - cognitive edge [Internet]: Cognitive Edge, 2017. http://cognitive-edge.com/basicmethods/prompting-question-design/ (cited 26 Jul 2017).

40. Cognitive Edge. SenseMaker [Internet]. 2017. http://cognitive-edge. com/sensemaker/ (cited 29 Jan 2017).

41. Bakhache N, Michael S, Roupetz S, et al. Implementation of a SenseMaker research project among Syrian refugees in: Glob Health Action.

42. Snowden DJ. Cognitive Edge [Internet]: Cognitive Edge Ltd, 2016. http://www.cognitive-edge.com (cited 16 Oct 2016).

43. Business Intelligence and Analytics. Tableau Software [Internet]. 2017. https://www.tableau.com/ (cited 26 May 2017).

44. IBM Analytics. IBM SPSS - IBM Analytics [Internet]. 2016. https:// www.ibm.com/analytics/us/en/technology/spss/ (cited 26 May 2017)

45. Webster L. Using statistics to help interpret patterns: Are my eyes tricking me? [Internet]: QED Insight, 2015. http://qedinsight.com/ 2015/06/04/are-my-eyes-tricking-me/ (cited 17 Jul 2017).

46. Webster L, Carroll M. November 2014 webinar: the art and science of story patterns [Internet]: QED Insight, 2014. http://qedinsight.com/ resources/library/november-2014-webinar/ (cited 17 Jul 2017).

47. DeLong S. Statistics in the triad, part II: log-ratio transformation [Internet]: QED Insight, 2016. http://qedinsight.com/2016/03/28/logratio-transformation/ (cited $17 \mathrm{Jul}$ 2017).

48. DeLong S. Statistics in the triad, part I: geometric mean [Internet] QED Insight, 2016. http://qedinsight.com/2016/03/28/geometricmean/ (cited $17 \mathrm{Jul}$ 2017).

49. The R Foundation. R: The R Project for Statistical Computing [Internet]. 2017. https://www.r-project.org/ (cited 26 May 2017).

50. DeLong S. Statistics in the triad, part IV: confidence regions [Internet]: QED Insight, 2017. http://qedinsight.com/2017/07/08/ confidence-regions/ (cited 26 Jul 2017).

51. United Nations Population Fund (UNFPA). Women and girls safe spaces: a guidance note based on experience from the Syrian crisis [Internet]: UNFPA, 2015. https://www.unfpa.org/sites/default/ files/resource-pdf/UNFPA UNFPA Women and Girls Safe Spaces Guidance \%5B1\%5D.pdf (cited 07 Nov 2017).

52. Human Trafficking Centre. Modern servitude beneath the guise of the islamic marriage contract | human trafficking centerHuman trafficking center [Internet]: Human Trafficking Centre, 2015. http:// humantraffickingcenter.org/modern-servitude-beneath-guise-islamic -marriage-contract/ (cited 30 Nov 2017).

53. DeJong J, El-Khoury G. Reproductive health of Arab young people. BMJ 2006;333:849-51.

54. DeJong J, Jawad R, Mortagy I, et al. The sexual and reproductive health of young people in the Arab countries and Iran. Reprod Health Matters 2005;13:49-59 https://www.tandfonline.com/doi/full/10. 1016/S0968-8080\%2805\%2925181-9

55. Kandiel A. European University Institute Robert Schuman Centre for Advance Studies. Gender and migration: the case of egypt [Internet], 2011. http://cadmus.eui.eu/bitstream/handle/1814/15599/CARIM ASN 2011 14.pdf?sequence $=1$ (cited 01 Dec 2017).

56. Zuhur S. Consideraions of honor crimes, FGM, kidnapping/rape and early marriage in selected Arab nations [Internet]: United Nations, 2009. http://www.un.org/womenwatch/daw/egm/vaw_legislation 2009/Expert Paper EGMGPLHP_Sherifa Zuhur - II_.pdf (cited 01 Dec 2017). 